\title{
Involvement of AP-1 and Steroidogenic Factor (SF)-1 in the cAMP-Dependent Induction of Human Adrenocorticotropic Hormone Receptor (ACTHR) Promoter
}

\author{
Devanand SARKAR, Fukushi KAMBE, Yoshitaka HAYASHI, Sachiko OHMORI, \\ Hiroomi FUNAHASHI* AND HISAO SEO
}

Department of Endocrinology and Metabolism, Research Institute of Environmental Medicine, Nagoya University, Furo-cho, Chikusa-ku, Nagoya 464-8601, Japan

* Department of Surgery II, Nagoya University School of Medicine, Tsurumai-cho, Showa-ku, Nagoya 466-8550, Japan

\begin{abstract}
Adrenocorticotropic hormone receptor (ACTHR) is expressed predominantly in the adrenal glands, and its expression is upregulated by its own ligand, ACTH, via a cAMP-dependent pathway. In the present study, we characterized the 5'-regulatory region of human ACTHR gene to elucidate the molecular mechanisms underlying its adrenal-specific and ACTH/cAMP-dependent expression. The promoter region $(-1017 /+47$ when the transcription start site is regarded as +1$)$ and its serial $5^{\prime}$-deletions $(-764 /+47,-503 /+47,-214 /+47$ and $-56 /+47)$ were ligated into the upstream of a luciferase (luc) reporter gene. These constructs were transfected into adrenocortical Y1 cells or non-adrenal JEG3 and Cos-1 cells. In all the cell lines, the luc activity gradually increased with serial 5 -deletions and the maximum activity was conferred by $-56 /+47$. However, the magnitude of luc activity of each deletion construct in non-adrenal cells was much less than that in Y1 cells, suggesting that the promoter functions in an adrenal-specific manner. We identified two Steroidogenic Factor (SF)-1-binding sites at -209 and -35 . Electrophoretic mobility shift assay (EMSA) demonstrated that both sites bind to SF-1. Mutation of both sites significantly decreased the activity of $-214 /+47$ promoter in Y1 cells. Transfection of SF-1-expressing plasmid into non-adrenal cells significantly increased the promoter activity, suggesting that SF-1 plays a role in the tissue-specific expression of human ACTHR gene. We identified the region, -764 to -503 , that was required for the forskolin/cAMP responsiveness of the promoter. This region contains one AP-1 site. EMSA revealed that the binding of AP-1 to this site increased significantly upon treatment of Y1 cells with forskolin. Mutation of the site abolished the forskolin-responsiveness. In non-adrenal cells, the forskolin-responsiveness was observed only when SF-1-expressing plasmid was cotransfected. This is the first demonstration that both AP-1 and SF-1 are required for the cAMP-dependent induction of human ACTHR gene.
\end{abstract}

Keywords: ACTH receptor, Promoter, SF-1, AP-1, cAMP

(Endocrine Journal 47: 63-75, 2000)

\begin{abstract}
ADRENOCORTICOTROPIC hormone (ACTH) regulates the basal secretion of glucocorticoids from adrenal cortex as well as their increased secretion evoked by stress [1]. ACTH exerts its effects through

Received: April 12, 1999

Accepted: November 17, 1999

Correspondence to: Dr. Hisao SEO, Department of Endocrinology and Metabolism, Research Institute of Environmental Medicine, Nagoya University, Furo-cho, Chikusa-ku, Nagoya 464-8601, Japan
\end{abstract}

its high-affinity receptor (ACTHR) on the plasma membrane of adrenocortical cells. ACTHR belongs to the seven-transmembrane domain superfamily of GTP-binding protein-coupled receptors [2]. Binding of ACTHR with its own ligand results in activation of adenylyl cyclase via stimulatory GTP-binding protein $\left(G_{s}\right)$, followed by an increase in intracellular cAMP which acts as the second messenger in the signal transduction pathway [2].

ACTHR is expressed mainly in the adrenal cortex, although its expression in lymphocytes, adipocytes 
and skin has been detected by RT-PCR or binding studies [3-5]. We, as well as others, have demonstrated that ACTHR mRNA level is increased by $\mathrm{ACTH} / \mathrm{cAMP}$ in rat adrenals in vivo and in bovine, mouse and human adrenocortical cells in vitro in a time- and dose-dependent manner [6-8]. Therefore, the expression of ACTHR gene must be regulated in a tissue-specific and ligand-responsive manner.

The human ACTHR gene consists of two exons: the second exon contains the entire coding sequence of ACTHR and the first exon, encoding 49-bp 5'. noncoding sequence, is separated from the second exon by an intron of approximately $18 \mathrm{~kb}$ in length $[9,10]$. The 5 -regulatory region lacks TATA- and CAAT-boxes, but an initiator-like element is present at the transcription start site [11]. In addition, one putative site for steroidogenic factor (SF)-1, also known as Ad4BP [12], is present at -35 bp in the promoter region (the transcription start site is regarded as +1$)$ [11].

SF-1, a member of the nuclear receptor superfamily, plays an important role in the transcriptional regulation of several genes coding for steroidogenic enzymes such as P450scc, P450c17, P45011 $\beta$ and P450aromatase [13-16]. In addition, it also regulates the expression of genes coding for steroidogenic acute regulatory protein (StAR), mullerian inhibiting substance, oxytocin, the $\alpha$-subunit of glycoprotein hormones, lutenizing hormone $\beta$ subunit, prolactin receptor, DAX-1 [DSS (dosage-sensitive sex reversal)-AHC (adrenal hypoplasia congenita) critical region of the $\mathrm{X}$ chromosome] and SR-B1 (scavenger receptor, class $B$, type 1 receptor) [17-24]. It has recently been shown that one SF-1 site in the mouse ACTHR promoter is important for its tissue-specific transcription [25].

The common pathway in the regulation of expression of adrenal-specific and steroidogenic genes is mediated by cAMP. One of the factors involved in this mediation is SF-1. However, the role of SF-1 varies depending on the genes and the species. SF-1, along with some other factor(s), mediates cAMPresponsiveness of $\mathrm{P} 450 \mathrm{scc}$ gene in human and cow but not in mouse and rat [13, 26-28]. Similarly, cAMP-mediated induction of StAR gene is conferred by SF-1 in human but not in mouse [17, 29]. It has been shown that the human ACTHR promoter activity is upregulated by treatment with adenylyl cyclase activator, forskolin, and SF-1 is implicated to play a role in this mechanism $[11,30]$

In the present study, we report that SF-1 plays an important role in the tissue-specific expression of human ACTHR gene and that both SF-1 and AP-1 are involved in its cAMP-dependent induction. Although it is well established that ACTH/cAMP induces the expression of fos/jun family genes, the functional significance of this induction has not been clarified [31-33]. Our observation that AP-1 is involved in the cAMP-responsiveness of human ACTHR promoter lends a physiological significance to the upregulation of Fos/Jun family proteins (AP1) in the adrenal glands.

\section{Materials and Methods}

\section{Isolation of human ACTH receptor gene promoter}

The 5'-regulatory region upstream of exon 1 of human ACTH receptor gene was isolated by using the Promoter-Finder DNA walking kit (Clontech, Palo Alto, CA). PCR was carried out according to the instructions provided by the manufacturer using the following anti-sense primers: 5 '-TCA GCT CTG AAG CAG GAA CTT TCT GG-3' and 5'-TCT GGG CAA AAT GAA TGA GAA GGA A-3'. A single, major PCR product of approximately $1 \mathrm{~kb}$ was obtained from one of the libraries. It was cloned into pGEM-T vector by TA cloning (Promega, Madison, WI). For the purpose of cloning into reporter vector, the same sequence was amplified from human genomic DNA using the primers having the restriction sites for NheI and $B g l I I$, sense 5'-GCT AGC CTG CAG GGC ATG TTG CGG AGG C-3' and anti-sense 5 '-AGA TCT TCA GCT CTG AAG CAG GAA C-3' (restriction sites for NheI and BglII are underlined) and cloned into pGEM-T vector (Promega). The cloned fragments were sequenced in both directions by ABI PRISM dye terminator cycle sequencing ready reaction kit (Perkin Elmer, Foster City, CA) [34].

\section{Constructions of plasmids}

A reporter plasmid $\mathrm{p}(-1017 /+47)$ was generated by ligating the amplified human ACTHR promoter fragment into the $N h e I / B g / I I$ sites in the multiple cloning sites of pGL3-basic luciferase reporter plas- 
mid (Promega) that contains no promoter. The number +1 corresponds to the transcription start site [11]. To make the deletion constructs, $\mathrm{p}(-1017 /+47)$ was digested with KpnI (located in the multiple cloning site of pGL3-basic) and BstXI (present at -764 in the promoter) for $\mathrm{p}(-764 /+47)$; with KpnI and NdeI (present at -503) for $\mathrm{p}(-503 /+47)$ and with KpnI and NsiI (present at -56$)$ for $\mathrm{p}(-56 /+47)$. The construct $\mathrm{p}(-1017 /+47 \Delta-764 /-56)$ was generated by digesting $\mathrm{p}(-1017 /+47)$ with BstXI and NsiI. $\mathrm{p}(-764 /+47 \Delta-503 /-56)$ was generated by digesting $\mathrm{p}(-764 /+47)$ with $N d e \mathrm{I}$ and NsiI. These digested plasmids were blunt-ended using $\mathrm{T} 4$ DNA polymerase and religated. $\mathrm{p}(-214 /+47)$, $\mathrm{p}(-214 /+47 \mathrm{dSF} 1 \mathrm{~m})$ and $\mathrm{p}(-56 /+47 \mathrm{SF} 1 \mathrm{~m})$ were generated by PCR using the primers: sense 5 -GCT AGC GGA AGT AAC CTT GAC TAG CTG AGC3', 5'-GCT AGC GGA AGT AAT TTT GAC TAG CTG AGC-3', and 5'-GCT AGC GTG ATG CAT GTG TTC CGG CCC TTC CCG GCC CAT TGT CCA CTT GCT TGC T-3', respectively, and antisense 5'-AGA TCT TCA GCT CTG AAG CAG GAA C-3' (mutated bases are underlined). $\mathrm{p}(-214 /+47 \mathrm{pSF} 1 \mathrm{~m})$ and $\mathrm{p}(-214 /+47 \mathrm{dmut})$ were generated by swapping the $N$ si $/ \mathrm{Bg} / \mathrm{II}$ digested fragment from $\mathrm{p}(-56 /+47 \mathrm{SF} 1 \mathrm{~m})$ into $\mathrm{p}(-214 /+47)$ and $\mathrm{p}(-214 /+47 \mathrm{dSF} 1 \mathrm{~m})$, respectively. The fragment $-764 /-503$ containing mutation in the AP-1 site was amplified by PCR using the primers: sense 5'-GGT ACC TTG GCA CCA GCC CCA AAA ACC-3' and antisense 5'-ATG CAT TAA CCG CGG TGG GTC CAG ACA AG-3' (mutated bases are underlined) and it was ligated to $\mathrm{p}(-56 /+47)$ to generate $\mathrm{p}(-764 /+47 \Delta-503 /-56 \mathrm{AP} 1 \mathrm{~m}) . \quad \mathrm{p}(-764 /+47 \Delta$ $-503 /-56 \mathrm{pSF} 1 \mathrm{~m})$ was generated by swapping the NsiI/BglII digested fragment from $\mathrm{p}(-56 /+47$ SF1m) into $\mathrm{p}(-764 /+47)$. The resultant construct was digested with $N d e I$ and NsiI, blunt-ended and re-ligated. The full-length bovine cDNA for SF-1, also known as Ad4BP, was a generous gift from Dr. K. Morohashi (National Institute for Basic Biology, Okazaki, Japan). The plasmid pSF1Ex was generated by ligating the bovine Ad4BP cDNA into EcoRI/XbaI sites of pcDNAI/Amp (Invitrogen, San Diego, CA). The authenticity of all the constructs was ascertained by sequencing and restriction enzyme digestion.

\section{Cell culture, transfection and luciferase assay}

Y1 cells were cultured in F-10 (Life Technologies, Grand Island, NY) medium supplemented with 15\% horse serum, $2.5 \%$ fetal calf serum, 50 units $/ \mathrm{ml}$ of penicillin $\mathrm{G}$ and $50 \mu \mathrm{g} / \mathrm{ml}$ of streptomycin. JEG3 cells were cultured in Opti-MEM (Life Technologies) medium supplemented with $2 \%$ fetal calf serum, $50 \mathrm{units} / \mathrm{ml}$ of penicillin $\mathrm{G}$ and $50 \mu \mathrm{g} / \mathrm{ml}$ of streptomycin. Cos-1 cells were cultured in Dulbecco's modified Eagle medium (DMEM; Nissui, Tokyo, Japan) supplemented with $10 \%$ fetal calf serum, $50 \mathrm{units} / \mathrm{ml}$ of penicillin $\mathrm{G}$ and $50 \mu \mathrm{g} / \mathrm{ml}$ of streptomycin. All the cells were maintained at $37^{\circ} \mathrm{C}$ in $5 \% \mathrm{CO}_{2}$ and $100 \%$ relative humidity. The day before transfection, cells were plated on 12-well plates at 50,000 cells per well. Transient transfections were carried out using calcium-phosphate precipitation method with $1 \mu \mathrm{g}$ of reporter plasmid with or without $1 \mu \mathrm{g}$ of pSF1Ex and $0.1 \mu \mathrm{g}$ of $\mathrm{pSV} \beta$-gal (Promega). In all the cases, the total amount of DNA was kept constant by addition of pcDNAI/Amp carrying no cDNA inserts. After overnight exposure to the DNA-CaPO ${ }_{4}$ precipitate, the medium was removed and medium with or without $10 \mu \mathrm{M}$ forskolin (Wako, Tokyo, Japan) was added. Thirty-six hours after transfection, the cells were lysed by the addition of $100 \mu \mathrm{l}$ glycylglycine buffer $(25 \mathrm{mM}$ glycylglycine pH 7.8, 15 mM $\mathrm{MgSO}_{4}, 4 \mathrm{mM}$ EGTA, $1 \mathrm{mM}$ DTT) containing $0.2 \%$ Triton $\mathrm{X}-100$. Twenty $\mu \mathrm{l}$ aliquots were mixed with $300 \mu$ l of glycylglycine buffer containing $2 \mathrm{mM}$ ATP and $15 \mathrm{mM}$ potassium phosphate [35]. One hundred $\mu \mathrm{l}$ of glycylglycine buffer containing $0.2 \mathrm{mM}$ d-luciferin was injected to the mixture using automatic device in LUMAT LB9501 (Berthold, Tokyo, Japan) and luciferase activity was measured for $10 \mathrm{sec}$. The $\beta$-galactosidase activity was measured using Luminescent $\beta$-gal detection kit (Clontech) and LUMAT LB9501 according to the instruction. Luciferase activity was normalized by $\beta$-galactosidase activity and the data from triplicate determinations were expressed as mean \pm SD. Statistical analysis was carried out by using one-way ANOVA followed by Fisher's protected least significant difference (PLSD) analysis. 


\section{Nuclear extract preparation and Electrophoretic Mobility Shift Assay (EMSA)}

Nuclear extracts were prepared by the modified Schreiber's method as described previously [36]. Briefly, the cells were washed with PhosphateBuffered Saline (PBS) and lysed for $10 \mathrm{~min}$ in Buffer A $(10 \mathrm{mM}$ HEPES $\mathrm{pH} 7.9,10 \mathrm{mM} \mathrm{KCl}, 1.5 \mathrm{mM}$ $\mathrm{MgCl}_{2}, 1 \mathrm{mM}$ EDTA, $1 \mathrm{mM}$ dithiothreitol, $0.1 \%$ Nonidet P-40). After centrifugation, the pellet containing nuclei was lysed in Buffer B (20 mM HEPES pH 7.9, $400 \mathrm{mM} \mathrm{KCl}, 20 \%$ glycerol, $1 \mathrm{mM}$ EDTA, $1 \mathrm{mM}$ DTT). Both the buffers also contained $1 \mathrm{mM}$ PMSF, $1 \mu \mathrm{M}$ pepstatin A and $10 \mu \mathrm{g} / \mathrm{ml}$ leupeptin. After centrifugation the supernatant was collected as the nuclear fraction and stored at $-80^{\circ} \mathrm{C}$.

Oligonucleotides for EMSA were prepared by an- nealing the sense- and anti-sense -oligonucleotides and by extending the nucleotides with Klenow enzyme in the presence of $\left[\alpha-{ }^{32} \mathrm{P}\right] \mathrm{dCTP}(3000 \mathrm{Ci} / \mathrm{mmol}$; New England Nuclear, Boston, MA). The sequences of the oligonucleotides are shown in Table 1. Ten $\mu \mathrm{g}$ of nuclear extracts were incubated in a final volume of $25 \mu \mathrm{l}$ containing $40 \mathrm{mM}$ HEPES-KOH $\mathrm{pH} 7.9$, $75 \mathrm{mM} \mathrm{KCl}, 0.2 \mathrm{mM}$ EDTA, $10 \%$ glycerol, $0.5 \mathrm{mM}$ DTT, $2 \mu \mathrm{g}$ of poly(dI-dC) (Pharmacia, Piscataway, $\mathrm{NJ}$ ) for $10 \mathrm{~min}$ at room temperature and then $20,000 \mathrm{cpm}$ labeled probe was added and incubated for another $20 \mathrm{~min}$ at room temperature. For competition studies cold probes were added 15 minutes before the labeled probe. For supershift analysis the binding mixture was incubated with $1 \mu \mathrm{l}$ of antibody for 1 hour at $4^{\circ} \mathrm{C}$. Anti-SF-1 antibody was a kind gift from Dr. K. Morohashi. Anti-Fos family and anti-Jun family antibodies were purchased from
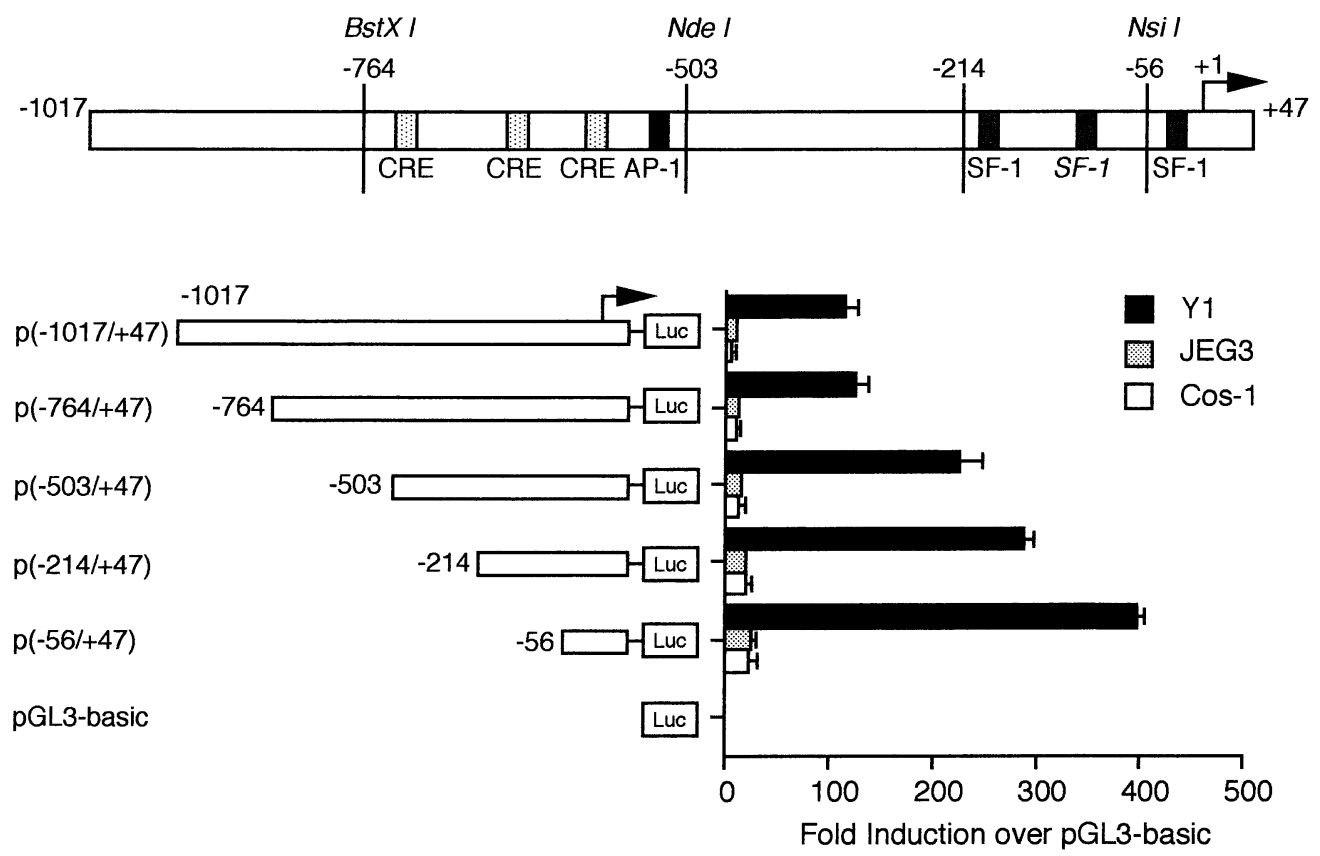

Fig. 1. Functional characterization of human ACTHR promoter.

The upper panel schematically shows the promoter region $(-1017 /+47)$ of human ACTHR gene. The small boxes in the promoter represent the putative cis-regulatory elements pertinent to the present study. The putative SF-1 site in italic has been shown not to bind to SF-1 in this study. The promoter region and its 5 -deletion fragments were ligated into the luciferase reporter plasmid. The restriction enzymes used to obtain 5 -deletion fragments and their positions are shown at the top $(+1$ corresponds to the transcription start site). The lower panel shows the relative luciferase activities of the ACTHR promoter-luciferase (Luc) construct $[\mathrm{p}(-1017 /+47)]$, its serial 5 -deletion constructs, and the promoterless plasmid (pGL3-basic). Each construct and $\beta$-galactosidase-expressing plasmid were transfected into Y1, JEG3 or Cos- 1 cells. Luciferase activity was measured 36 hours after transfection and was corrected by $\beta$-galactosidase activity. The activity of pGL3-basic was regarded as one. The data from triplicate determinations were expressed as mean \pm SD. Similar results were obtained from four separate experiments. 
Santa Cruz Biotech, Santa Cruz, CA. Free and bound DNA was separated on a $4 \%$ non-denaturating polyacrylamide gel in $0.5 \mathrm{X}$ Tris-borate-EDTA at a constant voltage of $165 \mathrm{v}$. The gel was dried on filter paper and exposed to Fujifilm Rx-U (Fuji, Tokyo, Japan) at $-80^{\circ} \mathrm{C}$ with an intensifying screen. Quantitative analysis was carried out by BAS 2000 Fujix Bioimage Analyzer (Fuji).

\section{Results}

Human ACTHR promoter $(-1017 /+47)$ was cloned into a luciferase (luc) reporter plasmid (pGL3-basic) and the construct was named $\mathrm{p}(-1017 /+47)$ as shown in Fig. 1. This construct and its serial $5^{\prime}$-deletion constructs, $\mathrm{p}(-764 /+47)$, $\mathrm{p}(-503 /+47), \mathrm{p}(-214 /+47)$ and $\mathrm{p}(-56 /+47)$, were transfected into adrenocortical Y1 cells or nonadrenal JEG3 and Cos-1 cells to examine the adrenal-specificity of the promoter. The luc activities of promoterless pGL3-basic were similar in all three cells. Introduction of ACTHR promoter sequences upstream of the reporter gene resulted in a dramatic increase in luc activities in Y1 cells. The magnitude of the luc activity of each construct in Y1 cells was markedly higher than that in JEG3 and Cos-1 cells, suggesting that the ACTHR promoter functions in an adrenal-specific manner. With serial 5 -deletions, the luc activities gradually increased in Y1 cells, and the maximum activity (approximately 400-fold above the activity of pGL3-basic) was shown by $\mathrm{p}(-56 /+47)$. To a lesser extent, similar increase in luc activities with serial deletions was observed in non-adrenal JEG3 and Cos-1 cells, suggesting the presence of some silencer region(s) upstream of -56 which may function ubiquitously.

The major factor conferring tissue-specificity to adrenal-specific as well as steroidogenic genes is SF-1 [13-16]. We identified three putative SF-1-binding sites in human ACTHR promoter at positions - 209, -98 and -35 , which we termed as distal (dSF1), middle (SF1mid) and proximal (pSF1) SF-1 sites, respectively. Fig. 2 shows a comparative analysis of the sequences of the promoter region and exon 1 in human and mouse ACTHR genes [11, 25]. They share a $69 \%$ homology, and the three putative SF-1 sites are fairly well-conserved. The dSF1 site is positioned in an inverse orientation in both species.

To determine whether SF-1 binds to these sites or

dSF1

H -223 ATAAACATTGGAAGTAACCTTGACTAGCTGAGCTCATGGAAATTATGTCTTCATCTGCCT

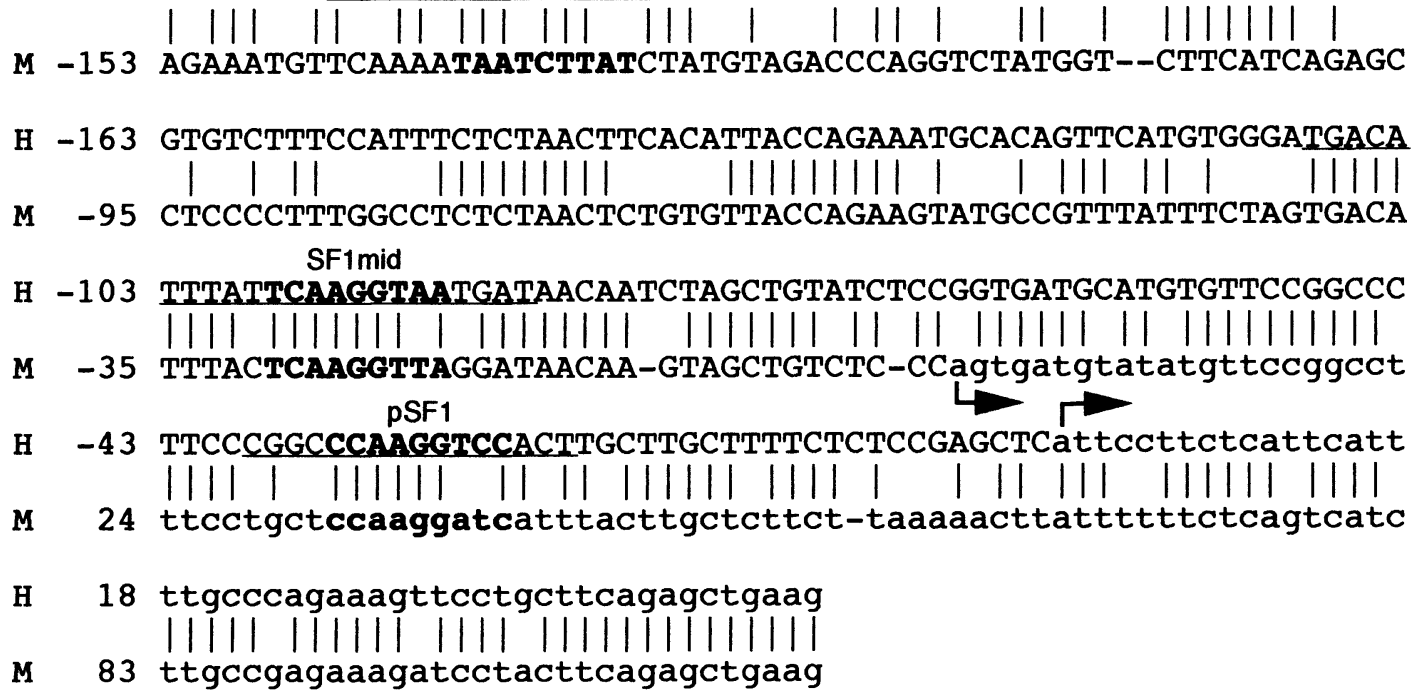

Fig. 2. Comparison between the sequences of human $(\mathrm{H})$ and mouse $(\mathrm{M})$ ACTHR promoter and exon 1.

The sequences of the promoter and exon 1 are shown in capital and small letters, respectively. The arrows indicate transcription start sites $(+1)$. Identical nucleotides are indicated by vertical lines. Three putative SF-1 sites, distal (dSF1), middle (SF1mid) and proximal (pSF1) sites, are shown in bold letters. The underlined sequences were used as probes for EMSA. 
not, we performed EMSA using nuclear extracts prepared from Y1 cells. As shown in Fig. 3A, a single protein/DNA complex was detected when pSF1 oligonucleotide was used as a probe. The complex was competed by cold pSF1 oligonucleotide at 100-fold molar excess, but not by the oligonucleotide with mutated SF-1 site (pSF1m) even at 500 -fold molar excess. In addition, the complex was eliminated by incubation with anti-SF-1 antibody [37], confirming that the complex contains either SF-1 or a protein antigenically similar to SF-1. Similarly, the SF-1 binding to the dSF1 site was demonstrated as shown in Fig. 3B. In mouse and also human ACTHR promoter, SF-1 has been shown to bind to the SF1mid site $[25,30]$. We observed several protein/DNA complexes using SF1mid oligonucleotide as a probe (Fig. 3C). To our surprise, all the complexes were not competed by cold dSF1 or pSF1 oligonucleotides even at 500 -fold molar excess, although they were displaced with cold SF1mid oligonucleotide. Anti-SF-1 antibody did not eliminate any complex. These results indicate that contrary to the previous report [30] the complexes do not include SF-1.

To examine the functional significance of the pSF1 and dSF1 sites in human ACTHR promoter, SF-1expressing plasmid, pSF1Ex, was cotransfected with reporter plasmids into non-adrenal JEG3 cells. As shown in Fig. 4A, expression of SF-1 resulted in more than two-fold increase in luc activity of $\mathrm{p}(-1017 /+47), \mathrm{p}(-503 /+47)$ and $\mathrm{p}(-214 /+47)$ which contain both dSF1 and pSF1 sites. We mutated the SF-1 sites in the construct $\mathrm{p}(-214 /$ $+47)$ and in $p(-56 /+47)$ to test the requirement of these sites in conferring tissue-specificity. $\mathrm{p}(-214 /+47 \mathrm{dSF} 1 \mathrm{~m})$ and $\mathrm{p}(-214 /+47 \mathrm{pSF} 1 \mathrm{~m})$, in which the distal and proximal SF-1 sites were mutated respectively, showed a 1.5 fold increase in luc ac-
A.

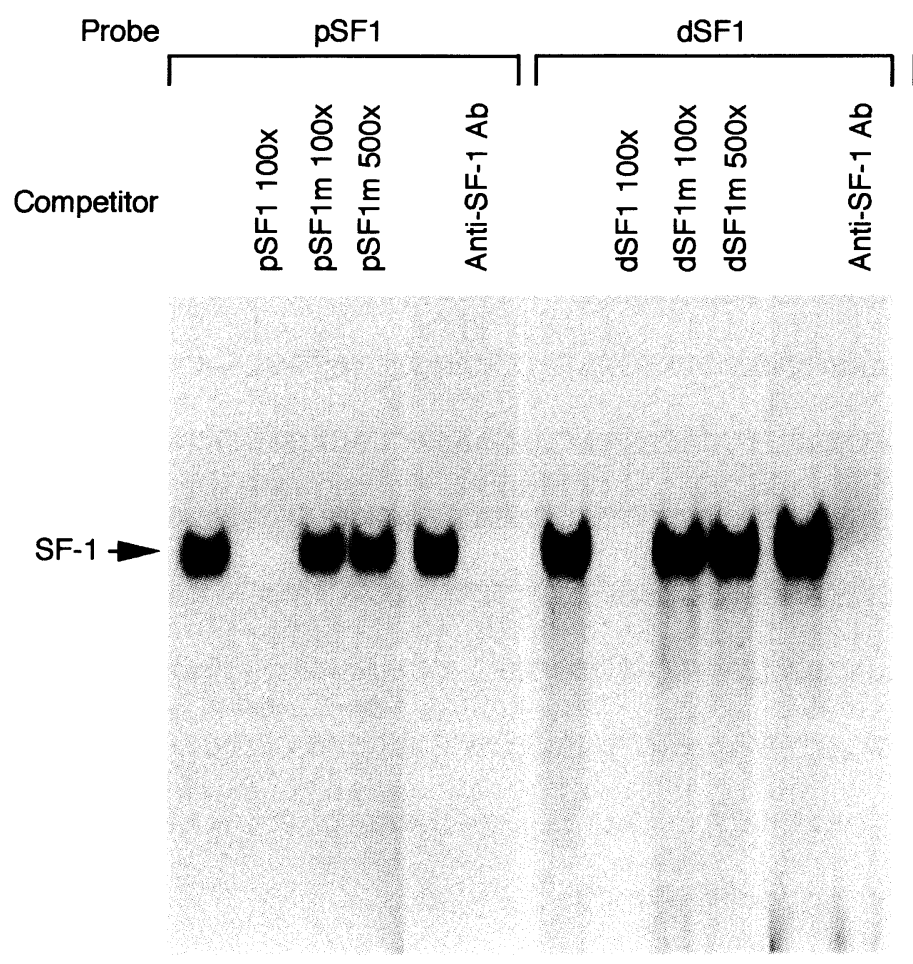

C.
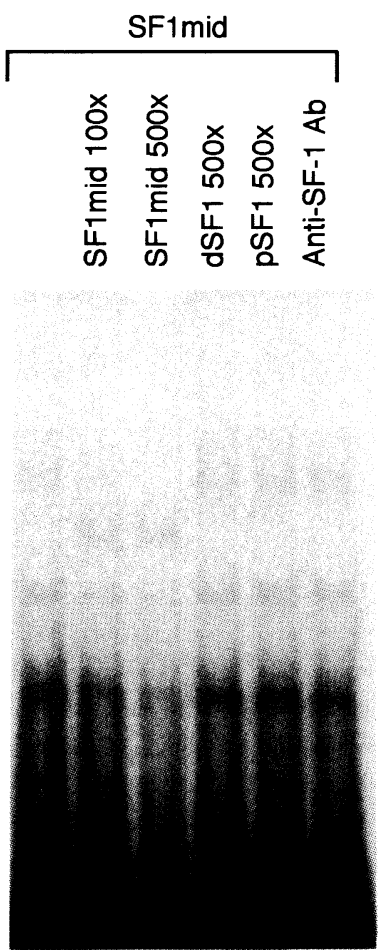

Fig. 3. SF-1 binds to pSF1 and dSF1 sites but not to SF1mid site.

EMSA was performed with pSF1 (panel A), dSF1 (panel B) and SF1mid (panel C) oligonucleotides as probes. Nuclear extracts $(10 \mu \mathrm{g} /$ lane) from Y1 cells were incubated with the labeled probes in the presence or absence of 100- or 500-fold molar excess of competitor oligonucleotides. The competitors pSF1m and dSF1m have a mutated SF-1 site (the sequences shown in Table 1). Supershift analysis was performed with anti-SF-1 antibody (Anti-SF-1 Ab). The band of SF-1/DNA complex is indicated by an arrow. Similar results were obtained from two separate experiments. 


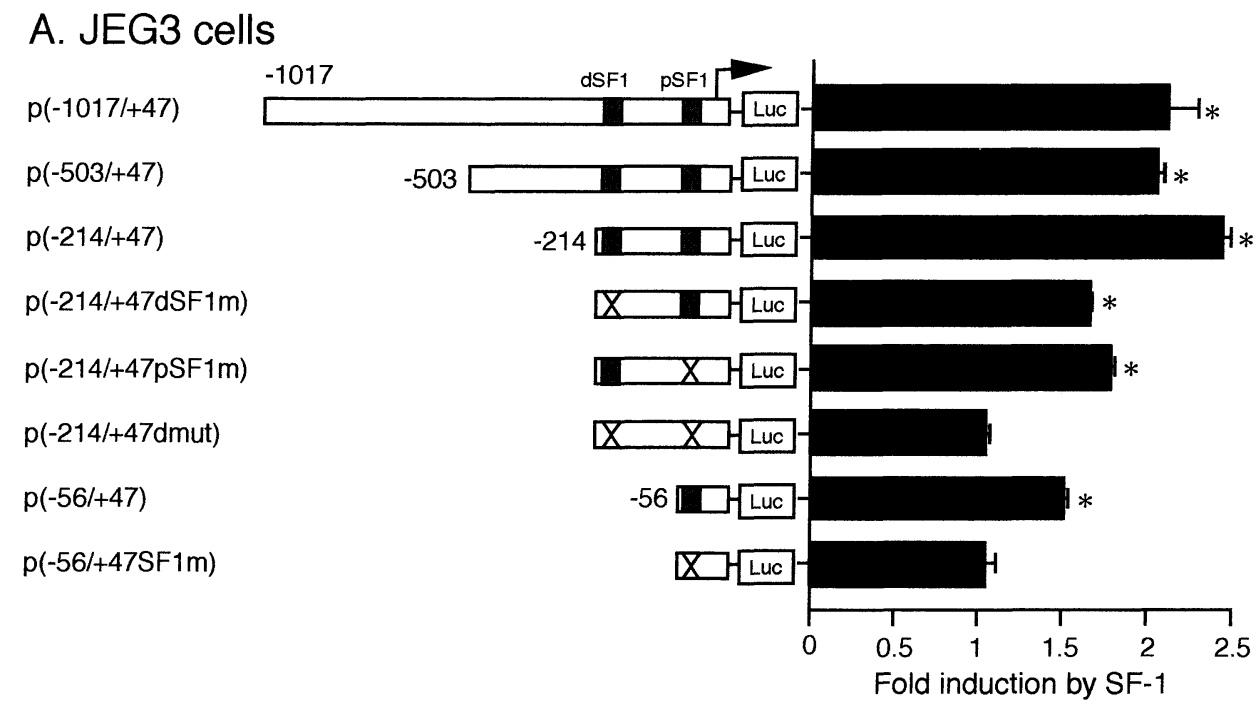

B. Y1 cells

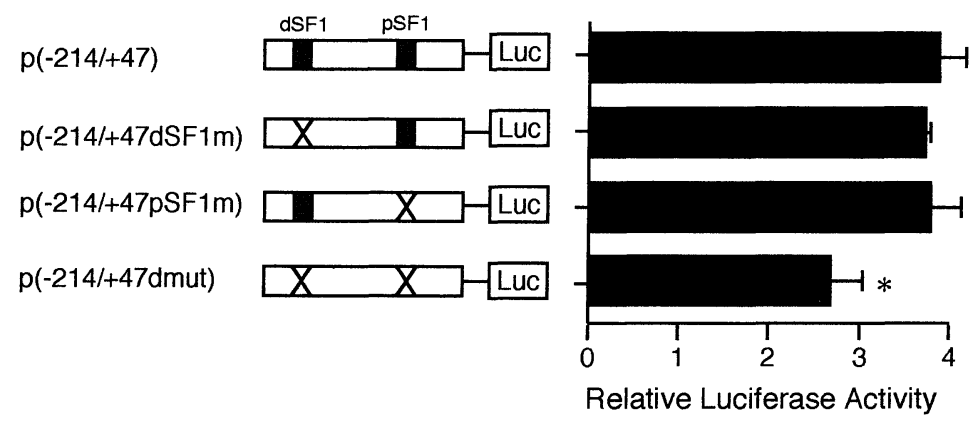

Fig. 4. Involvement of SF-1 in the ACTHR promoter activity.

Panel A. The ACTHR promoter-luciferase (Luc) constructs with or without mutation(s) at dSF1 and/or pSF1 sites were transfected into JEG3 cells alone or together with SF-1-expressing plasmid. dSF1 and pSF1 sites are indicated by the dotted boxes. The ' $\mathrm{X}$ ' indicates a mutated SF-1 site. The values were presented as fold induction by SF-1 when the luciferase activity in the absence of SF-1 was regarded as one. The data from triplicate determinations were expressed as mean $\pm \mathrm{SD}$. The asterisk represents a significant increase $(p<0.05)$ over the activity in the absence of SF-1. Similar results were obtained from two separate experiments. Panel B. $p(-214 /+47)$ and its SF-1 site mutants were transfected into Y1 cells. The values were presented as relative luciferase activity after the luciferase activity was normalized by $\beta$-galactosidase activity. The data from triplicate determinations were expressed as mean \pm SD. The asterisk represents a significant decrease $(p<0.05)$ versus $p(-214 /+47)$. Similar results were obtained from two separate experiments.

tivity in the presence of SF-1. Similar level of increase in luc activity was observed in $\mathrm{p}(-56 /+47)$ which contains only the pSF1 site. The SF-1-site null constructs, $\mathrm{p}(-214 /+47 \mathrm{dmut})$ in which both dSF1 and $\mathrm{pSF} 1$ sites were mutated, and $\mathrm{p}(-56 /+47 \mathrm{SF} 1 \mathrm{~m})$ in which pSF1 site was mutated, displayed no SF-1responsiveness.

When the mutated constructs were transfected into Y1 cells (Fig. 4B), mutation of either dSF1 or pSF1 did not alter the luc activity. Mutation of both sites significantly decreased the luc activity. These results indicate that interaction of SF-1 with either dSF1 or pSF1 site is important for the adrenal-specific expression of human ACTHR promoter.

Next we sought to determine which region confers cAMP/forskolin-responsiveness. As shown in Fig. 5 , transfection of $\mathrm{p}(-1017 /+47)$ and $\mathrm{p}(-764 /+47)$ resulted in a two-fold induction in luc activities upon stimulation by forskolin. Other 5 -deletion constructs, $\mathrm{p}(-503 /+47)$ and $\mathrm{p}(-56 /+47)$, showed no responsiveness to forskolin which is in contrast to the report by Naville et al. [11]. To confirm the 


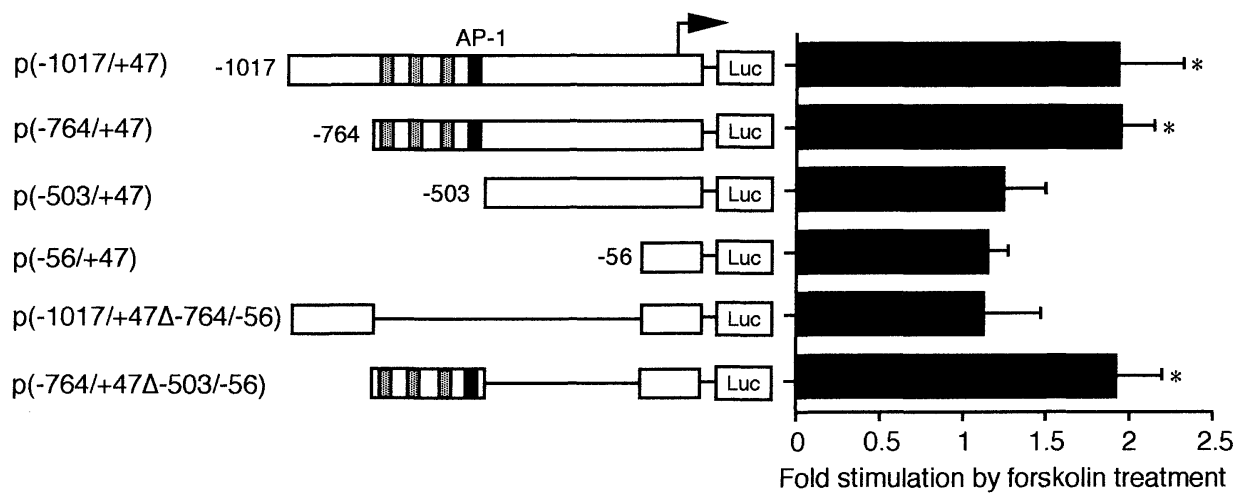

Fig. 5. Effect of forskolin on the activity of deletion constructs in Y1 cells.

The ACTHR promoter-luciferase (Luc) deletion constructs were transfected into Y1 cells. Twelve hours after transfection, the cells were treated with $10 \mu \mathrm{M}$ forskolin. The luciferase activity was measured 24 hours after the addition of forskolin. The dotted and black boxes represent putative CREs and AP1 site, respectively. The values were presented as fold increase by forskolin when the activity of cells without forskolin treatment was regarded as one. The data obtained from triplicate experiments are expressed as mean \pm SD. The asterisk represents a significant increase $(p<0.05)$ over the activity without forskolin. Similar results were obtained from two separate experiments.

authenticity of our observation, we made two additional constructs $\mathrm{p}(-1017 /+47 \Delta-764 /-56)$, in which -764 to -56 region was removed from $\mathrm{p}(-1017 /+47)$, and $\mathrm{p}(-764 /+47 \Delta-503 /-56)$, in which -503 to -56 region was removed from $p(-764 /+47)$. Since the construct $p(-764 /$
$+47 \Delta-503 /-56)$ also showed a two-fold induction by forskolin and $\mathrm{p}(-1017 /+47 \Delta-764 /-56)$ did not, we concluded that the region -764 to -503 is responsible for cAMP-responsiveness.

This region contains three putative cAMP-responsive elements (CREs) and one AP-1 site (Fig. 1). The
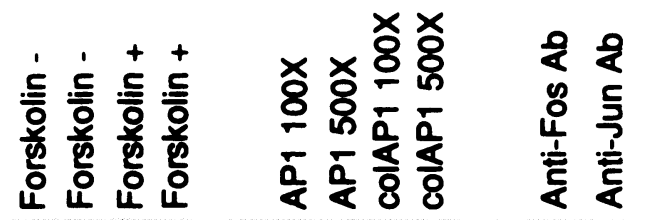
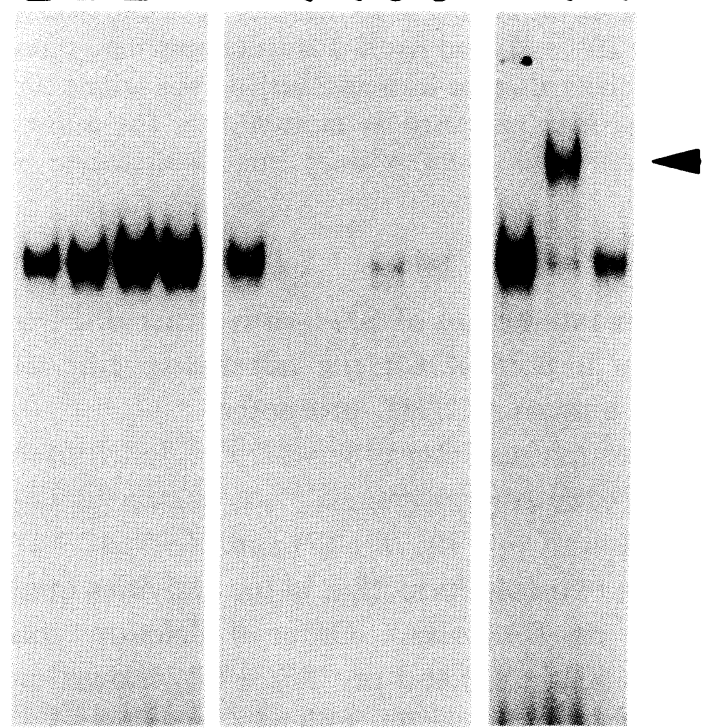

1234
Fig. 6. AP-1 binds to the consensus site in human ACTHR promoter.

EMSA was performed with nuclear extracts $(10 \mu \mathrm{g} / \mathrm{lane})$ from Y1 cells using the labeled AP1 oligonucleotide as a probe (Table 1). Y1 cells were incubated without (lanes 1 and 2) or with (lanes 3 and 4) $10 \mu \mathrm{M}$ forskolin for 24 hours and the nuclear extracts were subjected to EMSA. The competition study was performed using the extracts without forskolin (lanes 5-9). The unlabeled AP1 oligonucleotide (lanes 6 and 7) and colAP1 oligonucleotide (lanes 8 and 9), containing consensus AP-1 site in collagenase promoter, were used as competitors at 100 - or 500 -fold molar excess. Supershift analysis was carried out using the extracts with forskolin (lanes 10-12). Note that anti-Fos family antibody (Anti-Fos $\mathrm{Ab}$ ) supershifted the protein/DNA complex (lane 11) indicated by the arrowhead. In contrast, anti-Jun family antibody (Anti-Jun $\mathrm{Ab}$ ) markedly reduced the density of the complex (lane 12). Similar results were obtained from a separate experiment. 
Table 1. Sequences of probes and competitors

\begin{tabular}{|c|c|}
\hline dSF1: & $\begin{array}{l}5^{\prime} \text {-TGGAAGTAACCTTGACTA-3' } \\
3^{\prime} \text {-TCATTGGAACTGATCGAC-5' }\end{array}$ \\
\hline dSF1m: & $\begin{array}{l}5^{\prime} \text {-TGGAAGTAAttTTGACTA-3' } \\
\text { 3'-TCATTaaAACTGATCGAC-5' }\end{array}$ \\
\hline PSF1 : & $\begin{array}{l}5^{\prime} \text {-CGGCCCAAGGTCCACT-3' } \\
3^{\prime} \text {-GGTTCCAGGTGAACGA-5' }\end{array}$ \\
\hline pSF1m: & $\begin{array}{l}5^{\prime} \text {-CGGCCCAttGTCCACT-3' } \\
3^{\prime} \text {-GGTaaCAGGTGAACGA-5' }\end{array}$ \\
\hline SF1mid: & $\begin{array}{l}5^{\prime} \text {-TGACATTTATTCAAGGTAATGAT-3' } \\
3^{\prime} \text {-TAAATAAGTTCCATTACTATTGT-5 }\end{array}$ \\
\hline AP1 : & $\begin{array}{l}5^{\prime} \text {-CTGGACCCATGCGTCATATGT-3' } \\
3^{\prime} \text {-TGGGTACGCAGTATACACGTG-5' }\end{array}$ \\
\hline COIAP1 : & $\begin{array}{l}5 \cdot \text {-TCGAGAGCATGAGTCAGACAG-3' } \\
\text { 3'-CTCGTACTCAGTCTGTCAGCT-5' }\end{array}$ \\
\hline
\end{tabular}

Consensus sequences in dSF1, pSF1, AP1 and colAP1 are indicated in bold letters.

Mutated bases are shown in small letters.

putative AP-1 site (TGCGTCA) lies at position -510. As shown in Fig. 6, EMSA using the AP-1 site as a probe revealed that the probe formed a single complex with Y1 nuclear extract. Interestingly, treatment of Y1 cells with forskolin induced a threefold increase in the intensity of the complex. This complex was competed by excess amounts of both cold AP-1 oligonucleotide and colAP1 oligonucleotide, containing a consensus AP-1 site present in the collagenase promoter (Table 1). We next performed supershift analysis using two antibodies, one recognizing all four members of the Fos family and the other recognizing all three members of the Jun family. Anti-Fos antibody supershifted the complex, while anti-Jun antibody, which is directed against the DNA-binding domain, markedly reduced the intensity of the complex. These results demonstrated that FOS/JUN heterodimer AP-1 binds to the AP-1 site at -510 . To determine the role played by AP-1 in cAMP-responsiveness, we made a construct $\mathrm{p}(-764 /+47 \Delta-503 /-56 \mathrm{AP} 1 \mathrm{~m})$ in which the putative AP-1 site was mutated and transfected into Y1 cells. As shown in Fig. 7, the basal activity of this construct decreased compared to that of $\mathrm{p}(-764 /+47 \Delta-503 /-56)$ and it also lost responsiveness to forskolin.

We also examined the role of SF-1 in this cAMPresponsiveness. As shown in Fig. 7, the construct $\mathrm{p}(-764 /+47 \Delta-503 /-56 \mathrm{pSF} 1 \mathrm{~m})$, in which the pSF1 site was mutated, showed decreased basal activity as well as no responsiveness to forskolin in Y1 cells. To extend our observation, we transfected $\mathrm{p}(-764 /+47 \Delta-503 /-56)$ with or without pSF1Ex in non-adrenal JEG3 cells. As shown in Fig. 8, $\mathrm{p}(-764 /+47 \Delta-503 /-56)$ showed forskolin-respon-

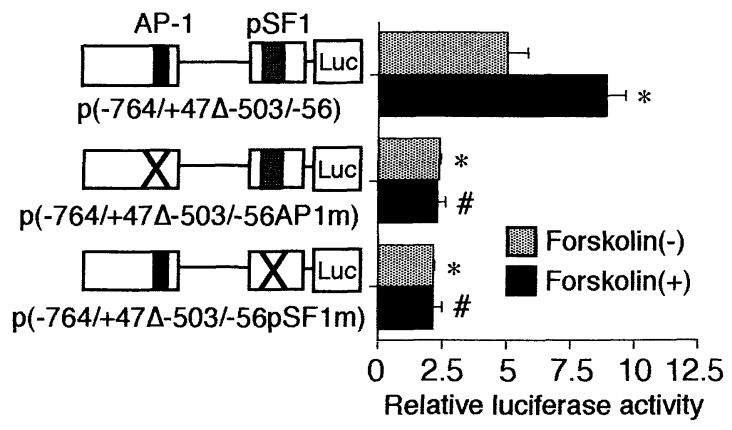

Fig. 7. Mutation in the AP-1 or pSF1 site abolishes the forskolin-responsiveness of ACTHR promoter in Y1 cells.

$\mathrm{p}(-764 /+47 \Delta-503 /-56)$ and its AP-1 or pSF1 mutant were transfected into Y1 cells. Twelve hours after transfection, the cells were treated with $10 \mu \mathrm{M}$ forskolin for 24 hours and then luciferase activity was measured. The values were presented as relative luciferase activity after the luciferase activity was normalized by $\beta$-galactosidase activity. The data from triplicate determinations are expressed as mean \pm SD. The asterisk represents significant changes $(\mathrm{p}<0.01)$ compared to the value of $\mathrm{p}(-764 /+47 \Delta$ $-503 /-56)$ without forskolin [forskolin $(-)]$. The sharp indicates a significant decrease $(\mathrm{p}<0.01)$ versus $\mathrm{p}(-764 /+47 \Delta-503 /-56)$ with forskolin [forskolin $(+)$ ]. Similar results were obtained from two separate experiments. 


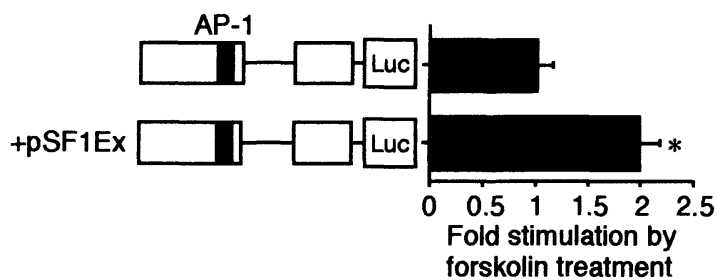

Fig. 8. SF-1 is required for the forskolin-responsiveness of ACTHR promoter in JEG3 cells.

$\mathrm{p}(-764 /+47 \Delta-503 /-56)$ were transfected into JEG3 cells with or without SF-1-expressing plasmid (pSF1Ex). Twelve hours after transfection the cells were treated with $10 \mu \mathrm{M}$ forskolin. The luciferase activity was determined 24 hours after the addition of forskolin. The values were presented as fold increase by forskolin when the luciferase activity of cells without forskolin treatment is regarded as one. The data from triplicate determinations are expressed as mean $\pm \mathrm{SD}$. The asterisk represents a significant increase $(p<0.05)$ compared to the value in the absence of pSF1Ex. Similar results were obtained from two separate experiments.

siveness only in the presence of SF-1, indicating that SF-1 is required for this responsiveness. Similar results were obtained from Cos-1 cells (data not shown).

\section{Discussion}

ACTH is the hormone which regulates the basal secretion of corticosteroids and also prepares the body to cope with stress by evoking an acute burst of corticosteroid secretion [1]. Since ACTH acts through its receptor, the factors that regulate ACTHR expression are crucial to the action of ACTH. The promoter region of human ACTHR gene was partially characterized by Naville et al. [11]. In the present study, we investigated in detail the role of cis-elements in human ACTHR promoter in adrenal-specific and sAMP-dependent transcriptional activation. We used $\mathrm{Y} 1$ cells as a representative of adrenal cells, and JEG3 and Cos-1 cells for nonadrenal cells. Surprisingly, contrary to the previous reports [11,30], we observed a gradual increase in the promoter activity with serial 5 '-deletions and the maximum activity was conferred by $\mathrm{p}(-56 /+47)$, indicating that some silencer regions are present upstream of -56 . It is of note that the sequences of the deletion mutants were verified and the experi- ments were performed multiple times with reproducible results. The promoter activity was markedly higher in Y1 cells than in JEG3 or Cos-1 cells, suggesting that the promoter functions in an adrenal-specific manner.

The binding site for SF-1 is present within a large number of steroidogenic genes and has been shown to be critical for their transcriptional activation in adrenal and gonadal cells. SF-1 binds as a monomer to the consensus sequence $5^{\prime}$-YCAAGGYY-3' or $5^{\prime}$ RRRAGGTCA-3' (Y: C or T, R: A or G) [12]. We identified three putative SF-1 sites in human ACTHR promoter and, by cotransfection studies, demonstrated that SF-1 significantly increased the promoter activity in non-adrenal JEG3 cells (Fig. 4), indicating that SF-1 is one of the tissue-specific elements involved in the regulation of the human ACTHR gene. Sequence alignment showed that all the three putative SF-1 binding sites in human and mouse ACTHR promoters are fairly well-conserved as shown in Fig. 2. Our EMSA and reporter gene analysis demonstrated that the distal and proximal SF-1 sites (dSF1 and pSF1 sites) are functional in the promoter (Fig. 3 and 4). Although the sequence of the middle SF-1 site (SF1mid) resembles a consensus SF-1 binding site, it did not bind to SF-1 (Fig. 3). Cammas et al. reported that the SF1mid site confers SF-1-responsiveness to the mouse promoter [25]. In a recent report, Naville et al. showed binding of SF-1 to the SF1mid site [30]. It is intriguing why SF-1 does not bind to the SF1mid site in the human promoter. The sequences of the SF1mid sites in mouse and human are 5'-TCAAGGTTA-3' and 5'-TCAAGGTAA-3', respectively. It is possible that the substitution of ' $\mathrm{T}$ ' at the 8th nucleotide by ' $\mathrm{A}$ ' in human abolished SF-1 binding. Morohashi et al. demonstrated that the presence of ' $C$ ' or ' $T$ ' at the 8th nucleotide is required for SF-1 binding and that substitution by ' $\mathrm{A}$ ' abolishes the binding [12]. Human dSF1 site ( 5 'TCAAGGTTA-3') has the same sequence as the mouse SF1mid further stressing the fact that one base-pair mismatch prevented SF-1 binding to human SF1mid. In Y1 cells, we observed that mutation of both dSF1 and pSF1 sites is required to significantly decrease the promoter activity (Fig. 4), suggesting that either one of these sites is sufficient to confer tissue-specificity to the ACTHR gene. Since mutation of both dSF1 and pSF1 sites did not abolish the basal activity of the promoter in $\mathrm{Y} 1$ cells, we might 
speculate the involvement of other yet uncharacterized promoter site(s) or factors in the basal and tissue-specific expression of human ACTHR gene.

A characteristic mechanism in the regulation of expression of human ACTHR gene is its upregulation by ACTH itself. It has been postulated that ACTH upregulates ACTHR mRNA by increasing either the transcription rate or mRNA stability $[38,39]$. We, therefore, sought to determine whether ACTH increases its own receptor expression at the level of transcription or not. Since the intracellular second messenger mediating ACTH action is cAMP, we used adenylyl cyclase activator, forskolin, to observe cAMP-dependent effect on the promoter activity. Treatment of Y1 cells with forskolin resulted in a two-fold increase in the promoter activity (Fig. 5) and the region $-764 /-503$ was found to be required for the forskolin-responsiveness of the promoter (Fig. 5). This region contains three putative CREs and one AP-1 site. However, the CREs are far less conserved than the consensus CRE (TGACGTCA) with 2 or 3 base-pair mismatches, whereas the AP-1 site (TGCGTCA) is well-conserved to the consensus AP1 site (TGAGTCA) [40, 41]. We previously demonstrated that a cAMP-dependent pathway is responsible for a rapid increase in c-fos mRNA by ACTH in primary culture of rat adrenal cells [33]. Our EMSA studies showed that AP-1 is constitutively expressed in Y1 cells and binding of AP-1 increased three-fold upon forskolin treatment. This result correlates with the result of luc assay showing that both the basal activity and CAMP-responsiveness of the promoter decrease with mutation of the AP-1 site. AP-1 has been shown to be involved in the zone-specific expression of the rat CYP11B1 gene [42]. However, there is no evidence that the CAMP-mediated induction of steroidogenic as well as adrenal-specific genes is conferred by AP-1. It is well established that ACTH induces the fos and jun family of genes but the physiological role has not been determined [ 31 , 32]. The present finding that AP-1 mediates the cAMP-dependent activation of the human ACTHR promoter depicts one of the physiological roles of AP-1 in adrenal glands.

SF-1 plays divergent roles in the cAMP-dependent regulation of different genes depending on the gene and the species. In some genes it acts alone, while in other genes it cooperates synergistically or additively with some other factors to confer cAMP responsiveness [13, 26-28]. In human ACTHR promoter, we demonstrated that SF-1 together with AP-1 mediates the cAMP-dependent activation of the promoter (Figs. 7 and 8). This is the first demonstration that SF-1 and AP-1 are cooperatively involved in the cAMP responsiveness and the underlying mechanism in this cooperation has yet to be clarified. Recently, both SF-1 and Sp-1 have been shown to be necessary for cAMP-stimulated expression of bovine CYP11A (P450scc) gene [27]. It has also been demonstrated by mammalian two-hybrid system that both factors exhibit physical interaction with each other. Thus, it might be possible that such a physical interaction between SF-1 and AP-1 is necessary for cAMP-dependent induction of human ACTHR promoter. On the other hand, it has been documented that SF-1 interacts with CBP [26]. Since c-fos and c-jun products also interact with CBP [43, 44], CBP might function as a bridging protein for both factors and thereby evoke cAMP-responsiveness. Further studies on the mechanism of interaction between SF-1 and AP-1 will lead to a better understanding of the role of these factors in transcriptional regulation of human ACTHR gene.

\section{Acknowledgments}

We thank Dr. K. Morohashi (National Institute for Basic Biology, Okazaki, Japan) for kindly providing SF-1 cDNA and anti-SF-1 antibody. This work was supported in part by Grants-in-Aid for Scientific Research from the Ministry of Education, Science, Sports and Culture, Japan.

\section{References}

1. Simpson ER, Waterman MR (1983) Regulation by ACTH of steroid hormone biosynthesis in the adrenal cortex. Canad J Biochem Cell Biol 61: 692-707.
2. Mountjoy KG, Robbins LS, Mortrud MT, Cone RD (1992) The cloning of a family of genes that encode the melanocortin receptors. Science 257: 1248-1251. 
3. Clarke BL, Bost KL (1989) Differential expression of functional adrenocorticotropic hormone receptors by subpopulations of lymphocytes. J Immunol 143: 464-469.

4. Boston BA, Cone RD (1996) Characterization of melanocortin receptor subtype expression in murine adipose tissues and in the 3T3-L1 cell line. Endocrinology 137: 2043-2050.

5. Slominski A, Ermak G, Mihm M (1996) ACTH receptor, CYP11A1, CYP17 and CYP21A2 genes are expressed in skin. J Clin Endocrinol Metab 81: 27462749.

6. Morita TM, Imai T, Murata Y, Kambe F, Funahashi H, Takagi H, Seo H (1995) Adrenocorticotropic hormone (ACTH) increases the expression of its own receptor gene. Endocrine $J$ 42: 475-480.

7. Penhoat A, Lebrethon MC, Begeot M, Saez JM (1995) Regulation of ACTH receptor mRNA and binding sites by ACTH and angiotensin II in cultured human and bovine adrenal fasciculata cells. Endocr Res 21: 157-168.

8. Mountjoy KG, Bird IM, Rainey WE, Cone RD (1994) ACTH induces up-regulation of ACTH receptor mRNA in mouse and human adrenocortical cell lines. Mol Cell Endocrinol 99: R17-R20.

9. Naville D, Barjhoux L, Jaillard C, Lebrethon MC, Saez JM, Begeot M (1994) Characterization of the transcription start site of the ACTH receptor gene: presence of an intronic sequence in the $5^{\prime}$-flanking region. Mol Cell Endocrinol 106: 131-135.

10. Clark AJ, Cammas FM (1996) The ACTH receptor. [Review] [82 refs]. Baillieres Clin Endocrinol Metab 10: 29-47.

11. Naville D, Jaillard C, Barjhoux L, Durand P, Begeot M (1997) Genomic structure and promoter characterization of the human ACTH receptor gene. Biochem Biophys Res Commun 230: 7-12.

12. Morohashi $\mathrm{K}$, Honda $\mathrm{S}$, Inomata $\mathrm{Y}$, Handa $\mathrm{H}$, Omura T (1992) A common trans-acting factor, Ad4-binding protein, to the promoters of steroidogenic P-450s. J Biol Chem 267: 17913-17919.

13. Clemens JW, Lala DS, Parker KL, Richards JS (1994) Steroidogenic factor-1 binding and transcriptional activity of the cholesterol side-chain cleavage promoter in rat granulosa cells. Endocrinology 134: 1499-1508.

14. Bakke M, Lund J (1995) Transcriptional regulation of the bovine CYP17 gene: two nuclear orphan receptors determine activity of cAMP-responsive sequence 2 . Endocr Res 21: 509-516.

15. Morohashi K, Zanger UM, Honda S, Hara M, Waterman MR, Omura T (1993) Activation of CYP11A and CYP11B gene promoters by the steroidogenic cell-specific transcription factor, Ad4BP. Mol Endocrinol 7: 1196-1204.
16. Carlone DL, Richards JS (1997) Evidence that functional interactions of CREB and SF-1 mediate hormone regulated expression of the aromatase gene in granulosa cells and constitutive expression in R2C cells. J Steroid Biochem Mol Biol 61: 223-231.

17. Sugawara T, Holt JA, Kiriakidou M, Strauss Jr (1996) Steroidogenic factor 1-dependent promoter activity of the human steroidogenic acute regulatory protein (StAR) gene. Biochemistry 35: 9052-9059.

18. Shen WH, Moore CC, Ikeda Y, Parker KL, Ingraham HA (1994) Nuclear receptor steroidogenic factor 1 regulates the mullerian inhibiting substance gene: a link to the sex determination cascade. Cell 77: 651-661.

19. Wehrenberg U, Ivell R, Jansen M, von Goedecke S, Walther N (1994) Two orphan receptors binding to a common site are involved in the regulation of the oxytocin gene in the bovine ovary. Proc Natl AcadSci USA 91: 1440-1444.

20. Barnhart KM, Mellon PL (1994) The orphan nuclear receptor, steroidogenic factor-1, regulates the glycoprotein hormone alpha-subunit gene in pituitary gonadotropes. Mol Endocrinol 8: 878-885.

21. Halvorson LM, Kaiser UB, Chin WW (1996) Stimulation of luteinizing hormone beta gene promoter activity by the orphan nuclear receptor, steroidogenic factor-1. J Biol Chem 271: 6645-6650.

22. Hu Z, Zhuang L, Guan X, Meng J, Dufau ML (1997) Steroidogenic factor-1 is an essential transcriptional activator for gonad-specific expression of promoter I of the rat prolactin receptor gene. J Biol Chem 272: 14263-14271.

23. Burris TP, Guo W, Le T, McCabe ER (1995) Identification of a putative steroidogenic factor-1 response element in the DAX-1 promoter. Biochem Biophys Res Commun 214: 576-581.

24. Cao G, Garcia CK, Wyne KL, Schultz RA, Parker KL, Hobbs HH (1997) Structure and localization of the human gene encoding SR-BI/CLA-1. Evidence for transcriptional control by steroidogenic factor 1 . J Biol Chem 272: 33068-33076.

25. Cammas FM, Pullinger GD, Barker S, Clark AJ (1997) The mouse adrenocorticotropin receptor gene: cloning and characterization of its promoter and evidence for a role for the orphan nuclear receptor steroidogenic factor 1. Mol Endocrinol 11: 867-876.

26. Monte D, DeWitte F, Hum DW (1998) Regulation of the human P450scc gene by steroidogenic factor 1 is mediated by CBP/p300. J Biol Chem 273: 4585-4591.

27. Liu Z, Simpson ER (1997) Steroidogenic factor 1 (SF-1) and SP1 are required for regulation of bovine CYP11A gene expression in bovine luteal cells and adrenal Y1 cells. Mol Endocrinol 11: 127-137.

28. Chau YM, Crawford PA, Woodson KG, Polish JA, Olson LM, Sadovsky Y (1997) Role of steroidogenic- 
factor 1 in basal and $3^{\prime}, 5^{\prime}$-cyclic adenosine monophosphate-mediated regulation of cytochrome P450 side-chain cleavage enzyme in the mouse. Biol Reprod 57: 765-771.

29. Caron KM, Ikeda Y, Soo SC, Stocco DM, Parker KL, Clark BJ (1997) Characterization of the promoter region of the mouse gene encoding the steroidogenic acute regulatory protein. Mol Endocrinol 11: 138-147.

30. Naville D, Penhoat A, Durand P, Begeot M (1999) Three steroidogenic factor-1 binding elements are required for constitutive and cAMP-regulated expression of the human adrenocorticotropin receptor gene. Biochem Biophys Res Commun 255: 28-33.

31. Viard I, Hall SH, Jaillard C, Berthelon MC, Saez JM (1992) Regulation of c-fos, c-jun and jun-B messenger ribonucleic acids by angiotensin-II and corticotropin in ovine and bovine adrenocortical cells. Endocrinology 130: 1193-1200.

32. Kimura E, Sonobe MH, Armelin MC, Armelin HA (1993) Induction of FOS and JUN proteins by adrenocorticotropin and phorbol ester but not by $3^{\prime}, 5^{\prime}$-cyclic adenosine monophosphate derivatives. Mol Endocrinol 7: 1463-1471.

33. Miyamoto N, Seo H, Kanda K, Hidaka H, Matsui N (1992) A 3',5'-cyclic adenosine monophosphate-dependent pathway is responsible for a rapid increase in c-fos messenger ribonucleic acid by adrenocorticotropin. Endocrinology 130: 3231-3236.

34. Hayashi Y, Ohmori S, Ito T, Seo H (1997) A splicing variant of Steroid Receptor Coactivator-1 (SRC-1E): the major isoform of SRC-1 to mediate thyroid hormone action. Biochem Biophys Res Commun 236: 83-87.

35. Hayashi Y, Yamaguchi S, Pohlenz J, Murata Y, Refetoff S, Seo H (1997) Modification of thyroid hormone and 9-cis retinoic acid signaling by overexpression of their cognate receptors using adenoviral vector. Mol Cell Endocrinol 131: 59-66.
36. Schreiber E, Matthias P, Muller MM, Schaffner W (1989) Rapid detection of octamer binding proteins with 'mini-extracts', prepared from a small number of cells. Nucleic Acids Res 17: 6419.

37. Hatano O, Takayama $\mathrm{K}$, Imai $\mathrm{T}$, Waterman $\mathrm{MR}$, Takakusu A, Omura T, Morohashi K (1994) Sex-dependent expression of a transcription factor Ad4BP, regulating steroidogenic $\mathrm{P}-450$ genes in the gonads during prenatal and postnatal rat development. Development 120: 2787-2797.

38. Penhoat A, Jaillard C, Saez JM (1994) Regulation of bovine adrenal cell corticotropin receptor mRNA levels by corticotropin (ACTH) and angiotensin-II (A-II). Mol Cell Endocrinol 103: R7-R10.

39. Penhoat A, Jaillard C, Begeot M, Durand P, Saez JM (1996) Cycloheximide enhances ACTH-receptor mRNA through transcriptional and post-transcriptional mechanisms in bovine adrenocortical cells. Mol Cell Endocrinol 121: 57-63.

40. Angel P, Karin M (1991) The role of Jun, Fos and the AP-1 complex in cell-proliferation and transformation. Biochim Biophys Acta 1072: 129-157.

41. Montminy MR, Sevarino KA, Wagner JA, Mandel G, Goodman RH (1986) Identification of a cyclicAMP-responsive element within the rat somatostatin gene. Proc Natl Acad Sci USA 83: 6682-6686.

42. Mukai K, Mitani F, Shimada H, Ishimura Y (1995) Involvement of AP-1 complex in zone-specific expression of the CYP11B1 gene in the rat adrenal cortex. Mol Cell Biol 15: 6003-6012.

43. Bannister AJ, Kouzarides T (1995) CBP-induced stimulation of c-Fos activity is abrogated by E1A. EMBO J 14: 4758-4762.

44. Bannister AJ, Oehler T, Wilhelm d, Angel P, Kouzarides T (1995) Stimulation of c-Jun activity by CBP: c-Jun residues Ser63/73 are required for CBP induced stimulation in vivo and CBP binding in vitro. Oncogene 11: 2509-2514. 